\title{
ESQUEMATISMO, MÍMESE E FALSA PROJEÇÃO: O MODO DE OPERAÇÃO DA INDÚSTRIA CULTURAL E SUAS CONSEQUENNCIAS
}

Schematism, mimesis and false projection: the way of working culture industry and its consequeces

Marcos Aurélio Corsini *

Resumo: Este artigo defende uma possibilidade de leitura que aponta para o fato de que a teoria do esquematismo kantiano, da mimese e do mecanismo da falsa projeção - como foram apresentados por Adorno e Horkheimer constituem-se como umas das principais ferramentas para se compreender o modo de operação da indústria cultural e suas consequências ocasionadas no indivíduo.

Palavras-chave: Indústria cultural;

esquematismo; mímese; falsa projeção
Abstract: This paper aims to defend a possibility of interpretation that leads to the fact that the Kantian Schematic Theory, mimesis and false projection - as presented by Adorno and Horkheimer - establish a major tool for the comprehension of the means of the cultural industry operation and its consequences produced in the individual.

Key-Words: Culture industry, schematism, mimesis, false projection.

* Mestrando em Filosofia pela Universidade Estadual de Maringá (UEM) Email: marcos_corsini@ hotmail.com

\begin{tabular}{|c|c|l|l|l|l|}
\hline intuitio & $\begin{array}{c}\text { ISSN } \\
1983-4012\end{array}$ & Porto Alegre & Vol.8 $-\mathrm{N}^{\circ} .1$ & $\begin{array}{c}\text { Junho } \\
2015\end{array}$ & p.276-295 \\
\hline
\end{tabular}




\section{Introdução}

A teoria do esquematismo kantiano na obra de Adorno e Horkheimer já foi explorada por Rodrigo Duarte e outros autores. Recoloco, assim, outra breve abordagem do conceito, agora com o intuito de pensar a teoria do esquematismo, junto à questão da mimese e do mecanismo da falsa projeção, como complementos do capítulo sobre a indústria cultural, dentro da Dialética do Esclarecimento, que visam explicar, por sua vez, o modo de operação da indústria cultural e as consequências que acarreta no indivíduo.

Desse modo, na primeira parte, faço uma breve reconstrução do conceito de esquematismo como aparece na Crítica da razão pura de Kant - explicando que o conceito se apresenta como uma espécie de termo médio, uma intersecção entre as intuições e os conceitos puros do entendimento que é responsável por sintetizar representações particulares através da intuição - para depois mostrar como o conceito é usado por Adorno e Horkheimer para explicar parte do modo de operação da indústria cultural sobre o indivíduo e como a indústria cultural se coloca como produtora de esquemas.

Na segunda parte, igualmente como na primeira, reconstruo brevemente o mecanismo da projeção de acordo com o texto intitulado "Notas psicanalíticas sobre um relato autobiográfico de um caso de paranoia" de Freud - apresentando a projeção como uma operação onde o indivíduo expulsa de si e localiza no outro indivíduo (ou coisa) as qualidades, desejos e sentimentos que estão dentro de si, mas que ele não admite que lhe são pertencentes - a fim de poder facilitar para o leitor a interpretação da falsa projeção e como este conceito se relaciona com a mimese e com a indústria cultural.

$\mathrm{Na}$ terceira parte do artigo, seguindo o caminho já percorrido por Rodrigo Duarte, explico como Adorno e Horkheimer fazem uso do esquematismo kantiano, apontando para o fato de que é a própria indústria cultural que produz os esquemas, uma vez que as pessoas acabam se orientando por produtos massificados que já são pré-digeridos. Os produtos são fabricados para o consumo: são fabricados segundo os padrões do próprio entendimento, pois a indústria cultural é a racionalização imposta do alto.

Em seguida, apresento o conceito de mimese, buscando mostrar que, através do fato do sujeito, naturalmente ou biologicamente, imitar a natureza, todo o comportamento humano acaba sendo compreendido como mimético, fazendo com que a indústria cultural, mediante a criação de fórmulas, estabeleça-se como meio de dominação: imprimindo moldes que são facilmente assimilados e imitados.

Por último, após a explicação do modo de operação da indústria cultural sobre o indivíduo mediante o esquematismo e a mimese -, apresento uma das consequências ocasionadas pela indústria cultural no indivíduo: a falsa projeção. Assim sendo, depois de esclarecer que a projeção é um mecanismo

\begin{tabular}{|c|c|l|l|l|l|}
\hline intuitio & $\begin{array}{c}\text { ISSN } \\
1983-4012\end{array}$ & Porto Alegre & Vol.8 $-\mathrm{N}^{\mathrm{o}} .1$ & $\begin{array}{c}\text { Junho } \\
2015\end{array}$ & p.276-295 \\
\hline
\end{tabular}


em que o indivíduo transfere seus impulsos para o objeto, e a falsa projeção um mecanismo em que o indivíduo, agora na condição de semiformado, é quem transfere seus impulsos patológicos para o objeto, explico que o homem realiza uma falsa projeção, ou projeção patológica, porque é semicultivado, posto que projeta um material derivado da semicultura. Portanto, partindo das considerações de Adorno e Horkheimer sobre a falsa projeção, concluo que o homem recebe, mediante a mimese, estímulos da cultura industrializada e, uma vez semiformado, projeta seus impulsos enquanto consumidor. Podendo se dizer que, no plano do nazismo, enquanto a paranoia é o sintoma do antissemita que persegue os judeus, no plano do mercado, ela também é o sintoma do sujeito contemporâneo que persegue, de modo doentio, os produtos.

\section{Kant e a teoria do esquematismo}

A segunda fase kantiana, intitulada "fase crítica", inicia-se com a Crítica da razão pura (Kritik der reinen Vernunft) publicada pela primeira vez em 1781. Em 1783, Kant escreve um texto de esclarecimento à sua primeira crítica, os Prolegômenos a toda metafísica futura que se queira apresentar como ciência ${ }^{2}$ (Prolegomena zu einer jeden künftigen Metaphysik die als Wissenschaft wird auftreten können), uma vez que o filósofo não ficou muito satisfeito com a recepção da obra anterior (a Crítica $d a$ razão pura). Nos Prolegômenos, Kant se propõe a responder a questão (que então já havia tratado na Crítica da razão pura) sobre a possibilidade da metafísica como ciência. Afirmando que a metafísica, até então, não poderia ter existido sem tais exigências que ele mesmo coloca na Crítica da razão pura, o filósofo afirma que a metafísica, enquanto ciência, ainda não havia ocorrido. Segundo Kant, o conteúdo da metafísica é a priori e as proposições sintéticas a priori constituem o objetivo da metafísica. De acordo com Kant, "[...] o verdadeiro problema da razão pura está contido na seguinte pergunta: como são possíveis os juízos sintéticos a priori?"3 Problema que é, com efeito, mencionado por Alexandre F. Morujão no prefácio da tradução portuguesa ${ }^{4}$. Sobre a questão central, portanto, Kant diz que, embora ainda não seja possível dizer que a metafísica seja real como ciência, pode-se afirmar que o conhecimento sintético puro a priori é real (como a matemática) ${ }^{5}$. No parágrafo quinto da advertência preliminar dos

\footnotetext{
${ }^{1}$ Utilizo a tradução de Manuela Pinto dos Santos e Alexandre Fradique Morujão, publicada pela editora Calouste Gulbenkian em 2001. Por convenção, todas as citações referentes à obra Crítica da razão pura aparecerão com o nome da obra abreviado (CRP) seguindo-lhe a paginação padrão, com preferência para a edição B.

${ }^{2}$ Utilizo a tradução de Tania Maria Bernkopf, publicada pela editora Abril Cultural em 1974.

${ }^{3}$ CRP, B 19.

4 “[...] o problema central, a tarefa geral da Crítica resumir-se-á em averiguar como são possíveis os juízos sintéticos a priori." Alexandre F. Morujão in Kant. "Prefácio da tradução portuguesa", Crítica da razão pura, p. 12.

${ }^{5}$ Kant. "Advertência preliminar a respeito das peculiaridades de todo conhecimento metafísico", Prolegômenos, p. 115.
}

\begin{tabular}{|c|c|l|l|l|l|}
\hline intuitio & $\begin{array}{c}\text { ISSN } \\
1983-4012\end{array}$ & Porto Alegre & Vol.8 $-\mathrm{N}^{\circ} .1$ & $\begin{array}{c}\text { Junho } \\
2015\end{array}$ & p.276-295 \\
\hline
\end{tabular}


Esquematismo, Mímese e falsa projeção: o modo de operação da indústria cultural e suas consequências

Prolegômenos, Kant se pergunta como são possíveis proposições sintéticas a priori, o que equivale a se perguntar como é possível o conhecimento pela razão pura. Para a solução da questão, é necessário se referir as duas únicas ciências do conhecimento teórico que podem nos apresentar os objetos na intuição: a matemática pura e a ciência pura da natureza. Assim, segundo Kant, a questão principal é dividida em quatro outras questões: “1) como é possível a matemática pura? 2) como é possível a ciência pura da natureza? 3) como é possível a metafísica em geral? 4) como é possível a metafísica como ciência?" ${ }^{6}$ Desse modo, a solução dessas tarefas propostas constitui

[...] o conteúdo essencial da Crítica, ela tem ao mesmo tempo algo peculiar, que por si só merece atenção, ou seja, levar a procurar as fontes das ciências dadas na própria razão, para assim investigar e medir pela própria ação o poder da razão de conhecer algo a priori $^{7}$.

A síntese dos juízos sintéticos a priori é obra da faculdade do entendimento, porém, o entendimento humano não é intuitivo, ao lado deste, Kant coloca uma faculdade intuitiva: a sensibilidade. Kant, no final da introdução da Primeira Crítica, diz "[...] que há dois troncos do conhecimento humano, porventura oriundos de uma raiz comum, mas para nós desconhecida, que são a sensibilidade e o entendimento; pela primeira são-nos dados os objetos, mas pela segunda são esses objetos pensados" ${ }^{\text {. }}$.

$\mathrm{Na}$ primeira parte da doutrina transcendental ${ }^{9}$ dos elementos, denominada "estética transcendental", Kant define a sensibilidade como "a capacidade de receber representações (receptividade), graças à maneira como somos afetados pelos objetos [...]" ${ }^{\prime 10}$ Somente a sensibilidade fornece ao homem as intuições (representações de fenômenos, "a representação que pode ser dada antes de qualquer pensamento [... $]^{\prime 11}$ ). As coisas que se podem conhecer graças às faculdades que o homem possui são dadas pelas formas da sensibilidade: o espaço e o tempo. O espaço, ao contrário de ser um conceito empírico ou uma forma das coisas pertencente a elas, "[...] é uma representação necessária, $a$ priori, que fundamenta todas as intuições externas"12. "O tempo é uma representação necessária que

\footnotetext{
${ }^{6}$ Kant. "Advertência preliminar a respeito das peculiaridades de todo conhecimento metafísico", Prolegômenos, p. 118.

${ }^{7}$ Kant. "Advertência preliminar a respeito das peculiaridades de todo conhecimento metafísico", Prolegômenos, p. 118.

${ }^{8}$ CRP, B 29.

9 Para se compreender o termo "transcendental", um trecho da introdução de Alexandre F. Morujão à edição portuguesa pode ajudar: "a filosofia [de Kant] deixa de ser uma ontologia, ultrapassa o cepticismo empirista e transforma-se em filosofia transcendental [...]", constituindo-se por uma filosofia que se preocupa menos com o objeto e mais com o modo de conhecer, investigando, inclusive, como esse é possível a priori. Alexandre F. Morujão in Kant. "Prefácio da tradução portuguesa", Crítica da razão pura, p. 12.

${ }^{10} \mathrm{CRP}, \mathrm{B} 33$.

${ }^{11}$ CRP, B 132.

${ }^{12}$ CRP, A 24.
}

\begin{tabular}{|c|c|l|l|l|l|}
\hline intuitio & $\begin{array}{c}\text { ISSN } \\
1983-4012\end{array}$ & Porto Alegre & Vol.8 $-\mathrm{N}^{\circ} .1$ & $\begin{array}{c}\text { Junho } \\
2015\end{array}$ & p.276-295 \\
\hline
\end{tabular}


Esquematismo, Mímese e falsa projeção: o modo de operação da indústria cultural e suas consequências

constitui o fundamento de todas as intuições"13. Dessa forma, "tomados conjuntamente são formas puras de toda a intuição sensível, possibilitando assim proposições sintéticas a priori" ${ }^{\prime 14}$.

Uma vez que a sensibilidade fornece a intuição, o entendimento fornece o conceito. Na segunda parte da doutrina transcendental dos elementos, denominada "lógica transcendental", Kant define o entendimento como "[...] a capacidade de produzir representações ou a espontaneidade do conhecimento" "15. Uma vez que a sensibilidade fornece a intuição sensível, o entendimento é o poder de pensá-la e, assim, ele não intui. Desse modo, o conhecimento surge da reunião da faculdade da sensibilidade (a capacidade do homem intuir) com a faculdade do entendimento (a capacidade do homem pensar).

A "Lógica", distinguida da ciência das regras da sensibilidade que é denominada de "Estética" e entendida como a ciência das regras do entendimento, é dividida em lógica geral e lógica transcendental. A lógica geral "[...] contém as regras absolutamente necessárias do pensamento [...]" "16, considera a forma lógica do pensamento e ignora todo conteúdo do conhecimento. A lógica transcendental desconsidera o conteúdo empírico, mas considera as intuições puras: o espaço e o tempo. Ela determina a origem objetiva do conhecimento, estuda a origem dos conceitos. Segundo Alexandre F. Morujão, “[...] à 'Estética' se segue a 'Lógica Transcendental', que vai esclarecer a possibilidade do conhecimento a priori e o alcance da sua validade" ${ }^{\prime 1}$. A lógica transcendental, por sua vez, se divide em analítica transcendental e dialética transcendental. A analítica transcendental “[...] apresenta os elementos do conhecimento puro do entendimento e os princípios, sem os quais nenhum objeto pode, em absoluto, ser pensado [...]"18 A dialética transcendental é uma "[...] crítica do entendimento e da razão, relativamente ao seu uso hiperfísico [...]"19 Uma crítica às ilusões e aos erros que a razão eventualmente cai.

Como a teoria do esquematismo (aqui primordial, posto que será mais tarde referida na Dialética do Esclarecimento de Adorno e Horkheimer) se encontra no segundo livro da analítica transcendental, intitulado "analítica dos princípios", esta exposição não explorará a parte da dialética transcendental, somente levantará os argumentos kantianos de importância capital para se compreender a teoria do esquematismo.

Na primeira divisão da lógica transcendental, denominada “Analítica Transcendental”, Kant faz uma "[...] decomposição de todo o nosso conhecimento a priori nos elementos do conhecimento puro do

\footnotetext{
${ }^{13}$ CRP, B 46.

${ }^{14}$ CRP, B 56.

${ }^{15}$ CRP, B 75.

${ }^{16}$ CRP, B 76.

${ }^{17}$ Alexandre F. Morujão in Kant. "Prefácio da tradução portuguesa", Crítica da razão pura, p. 14.

${ }^{18}$ CRP, B 87.

${ }^{19}$ CRP, B 88.
}

\begin{tabular}{|c|c|c|c|c|c|}
\hline intuitio & $\begin{array}{c}\text { ISSN } \\
1983-4012\end{array}$ & Porto Alegre & Vol.8 $-\mathrm{N}^{\mathrm{o}} .1$ & $\begin{array}{c}\text { Junho } \\
2015\end{array}$ & p.276-295 \\
\hline
\end{tabular}


Esquematismo, Mímese e falsa projeção: o modo de operação da indústria cultural e suas consequências

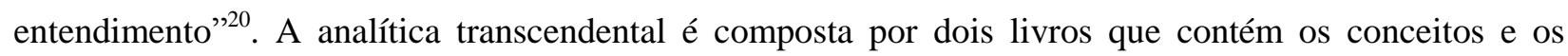
princípios do entendimento puro, respectivamente: “Analítica dos Conceitos" e "Analítica dos Princípios".

Assim, na analítica dos conceitos, Kant faz uma decomposição do conhecimento para investigar, no entendimento, a possibilidade dos conceitos a priori. O intelecto, além de poder pensar os conceitos (provenientes de intuições sensíveis), pode julgá-los. Dessa forma, reduzindo todas as ações do entendimento a juízos, Kant estabelece uma tabela de todas as formas lógicas possíveis que constitui todas as possibilidades de se unir sujeito e predicado num juízo; por conseguinte, as doze formas de juízos demonstradas corresponderão à tábua das categorias ${ }^{21}$. As categorias são os diferentes modos (conceitos puros) do entendimento operar uma síntese ${ }^{22}$ (uma "reconstrução" do objeto no entendimento) dos múltiplos dados advindos da intuição. As categorias são conceitos que fornecem leis aos fenômenos e é por meio delas que o homem pode pensar um objeto; elas, portanto, se relacionam a priori com os objetos da experiência ${ }^{23}$.

$\mathrm{Na}$ introdução da analítica dos princípios, Kant afirma que, sendo o entendimento uma faculdade passível de ser instruída por regras, a faculdade de julgar é a capacidade de subsumir (incluir) regras: a capacidade que alguns homens têm de discernir se algo está subordinado a uma regra ou não ${ }^{24}$, no entanto, a faculdade de julgar é um talento natural e não pode ser ensinada, restando à lógica transcendental guiar, com regras, a faculdade do homem de julgar.

Tendo Kant separado a "doutrina transcendental da faculdade de julgar” em dois capítulos, é o primeiro capítulo, intitulado "Do esquematismo dos conceitos puros do entendimento", que trata da condição sensível que permite o uso dos conceitos do entendimento: do esquematismo do entendimento puro. Desse modo, no capítulo sobre o esquematismo, Kant afirma que, em todas as inclusões de um objeto num conceito, a representação de um objeto tem de ser homogênea à representação do conceito; em outras palavras, um objeto deve estar contido (incluído) num conceito, ou ainda, um objeto particular (como um prato, por exemplo) deve estar contido num conceito universal (como o conceito "círculo"), assim se pode pensar o redondo (o conceito) e intuir o prato (o objeto) ${ }^{25}$. Porém, o problema é que os conceitos puros do entendimento, uma vez comparados com as intuições empíricas e sensíveis, são heterogêneos, na medida em que não se pode encontrá-los em nenhum lugar. Diante disso, Kant se pergunta como é possível a subsunção das intuições nos conceitos e afirma ser "[...] necessária uma doutrina transcendental da faculdade de julgar para mostrar a possibilidade de aplicar aos fenômenos em

\footnotetext{
${ }^{20}$ CRP, B 89.

${ }^{21}$ Alexandre F. Morujão in Kant. "Prefácio da tradução portuguesa", Crítica da razão pura, p. 14.

${ }^{22}$ A síntese é uma ação de ligação do entendimento, podendo ser uma ligação do diverso da intuição ou uma ligação de vários conceitos. CRP, B 130.

23 "Sendo assim, as categorias relacionam-se necessariamente e a priori com os objetos da experiência, pois só por intermédio destas em geral é possível pensar qualquer objeto da experiência." CRP, B 126.

${ }^{24}$ CRP, B 171-B 172.

${ }^{25}$ CRP, B 176.
}

\begin{tabular}{|c|c|c|c|c|c|}
\hline intuitio & $\begin{array}{c}\text { ISSN } \\
1983-4012\end{array}$ & Porto Alegre & Vol.8 $-\mathrm{N}^{\mathrm{o}} .1$ & $\begin{array}{c}\text { Junho } \\
2015\end{array}$ & p.276-295 \\
\hline
\end{tabular}


Esquematismo, Mímese e falsa projeção: o modo de operação da indústria cultural e suas consequências

geral os conceitos puros do entendimento" ${ }^{, 26}$. Kant, desse modo, diz que tem que haver um terceiro termo, homogêneo à categoria e ao fenômeno e que sirva de mediação aplicando a categoria (que faz a "reconstrução" do objeto no entendimento) ao fenômeno (objeto). Deve, também, ser - além de puro (não contendo nada de empírico) - intelectual e sensível: esse terceiro termo ou "representação mediadora" é o esquema transcendental:

É claro que tem de haver um terceiro termo, que deva ser por um lado, homogêneo à categoria e, por outro, ao fenômeno e que permita a aplicação da primeira ao segundo. Esta representação mediadora deve ser pura (sem nada de empírico) e, todavia, por um lado, intelectual e, por outro, sensível. Tal é o esquema transcendental ${ }^{27}$.

Para a aplicação da categoria ao fenômeno, Kant também chama atenção para a importância do tempo: a determinação transcendental do tempo é homogênea à categoria, porque é a priori, e é homogênea ao fenômeno, porque o tempo está contido em toda representação empírica. "Assim, uma aplicação da categoria aos fenômenos será possível mediante a determinação transcendental do tempo que, como esquema dos conceitos do entendimento, proporciona a subsunção dos fenômenos na categoria" 28 . Ainda que a imaginação também seja uma instância intermediária, ela não fornece uma regra que exprime a categoria, adequando-se, portanto, o esquema. Para uma melhor compreensão do esquema como uma mediação, acrescenta-se a seguinte reprodução gráfica:

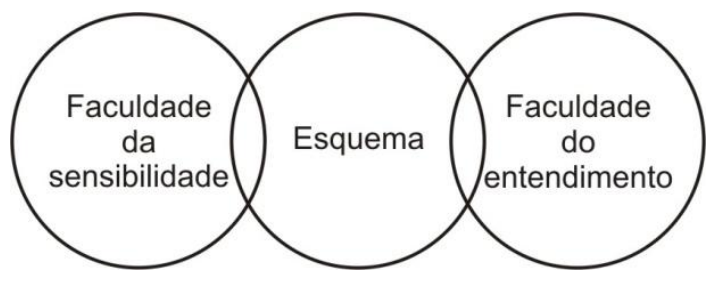

Kant dá o nome de "esquema" à condição formal e pura da sensibilidade (o terceiro termo intermediário) e de "esquematismo" do entendimento puro "[...] ao processo pelo qual o entendimento opera com esses esquemas" 29 . O esquema é uma espécie de termo médio, uma intersecção entre as intuições e os conceitos puros do entendimento, "de certa maneira, o esquema, na 'lógica transcendental', ocupa a função do 'termo médio', na 'lógica geral"’30. O esquema, para Kant, é um produto da imaginação, difere-se da imagem (produto da faculdade empírica) por ser esta um pensamento particular

${ }^{26}$ CRP, B 177.

${ }^{27}$ CRP, B 177.

${ }^{28} \mathrm{CRP}, \mathrm{B} 178$.

${ }^{29}$ CRP, B 179.

${ }^{30}$ Ubirajara R. de A. Marques. "Notas sobre o esquematismo na Crítica da razão pura de Kant”, p. 127.

\begin{tabular}{|c|c|l|l|l|l|}
\hline intuitio & $\begin{array}{c}\text { ISSN } \\
1983-4012\end{array}$ & Porto Alegre & Vol.8 $-\mathrm{N}^{\circ} .1$ & $\begin{array}{c}\text { Junho } \\
2015\end{array}$ & p.276-295 \\
\hline
\end{tabular}


Esquematismo, Mímese e falsa projeção: o modo de operação da indústria cultural e suas consequências

que por si só já fornece uma simples e única compreensão de um objeto, enquanto aquele é um pensamento de um conceito geral que, posteriormente, pode se referir, a priori, a várias imagens de objetos $^{31}$. Como exemplo, Kant diz que quando se dispõe cinco pontos um após o outro, tem-se uma imagem do número cinco, por outro lado, quando se pensa em um número, no número cem, por exemplo, esse número pensado é apenas um método que representa o conjunto que não pode ser compreendido pela vista, sendo assim, ele é um esquema - uma representação de um processo geral da imaginação que dá ao conceito (o número cem) a sua imagem.

Segundo Alexandre F. Morujão, "o esquema, ao contrário do que se poderia supor, não é uma

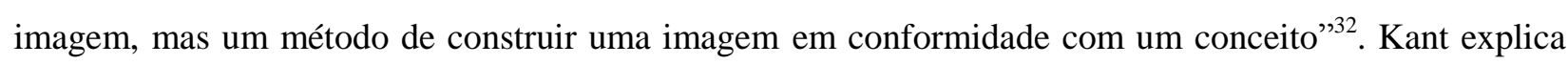
que o esquema de um conceito puro do entendimento não pode se reduzir a uma imagem em particular, pois ele é uma síntese pura feita de acordo com uma regra que exprime a categoria. Os esquemas são produtos transcendentais da imaginação, “[...] não são, pois, mais que determinações a priori do tempo, segundo regras [...]"33 Kant expõe o teor de importância dos esquemas ao afirmar que "os esquemas dos conceitos puros do entendimento são, pois, as condições verdadeiras e únicas que conferem a esses conceitos uma relação a objetos, portanto uma significação [...]"34

Uma vez ilustrado o que é o esquematismo, poder-se-á ver, na seção 3 deste artigo, como Adorno e Horkheimer utilizam essa teoria para explicar o modo de operação da indústria cultural. Porém, antes de se adentrar no texto dos autores frankfurtianos, será necessário reconstruir o mecanismo freudiano da projeção para, igualmente como a explicação do esquematismo, facilitar a compreensão do leitor para a teoria da falsa projeção que ainda será explicada.

\section{A teoria da projeção nas "Notas psicanalíticas" de Freud}

A projeção, hoje, considerando todas as áreas do conhecimento que dialogam com tal mecanismo, como a física, a fisiologia, a neurologia e a psicologia, concordam que se trata de um "[...] deslocamento de algo que no trajeto passa por alterações que resultam em algo 'novo', com alguma similaridade que o remete ao objeto original” ${ }^{35}$. Deve-se considerar que cada uma dessas áreas mencionadas toma a projeção de modo particular. Assim, a projeção, em Freud, é entendida como uma operação onde o indivíduo expulsa de si e localiza no outro indivíduo (ou coisa) as qualidades, desejos e sentimentos que estão dentro

\footnotetext{
${ }^{31}$ Kant diferencia imagem e esquema também com o exemplo do triângulo: “o esquema do triângulo só pode existir no pensamento e significa uma regra da síntese da imaginação com vista a figuras puras no espaço.” CRP, B 180 .

${ }^{32}$ Alexandre F. Morujão in Kant. "Prefácio da tradução portuguesa", Crítica da razão pura, p. 15.

${ }^{33}$ CRP, A 145.

${ }^{34}$ CRP, A $145-146$.

${ }^{35}$ Fonseca, A. L. B; Mariano, M. S. S. “Desvendando o mecanismo da projeção”, p. 2.
}

\begin{tabular}{|c|c|c|c|c|c|}
\hline intuitio & $\begin{array}{c}\text { ISSN } \\
1983-4012\end{array}$ & Porto Alegre & Vol.8 $-\mathrm{N}^{\mathrm{o}} .1$ & $\begin{array}{c}\text { Junho } \\
2015\end{array}$ & p.276-295 \\
\hline
\end{tabular}


Esquematismo, Mímese e falsa projeção: o modo de operação da indústria cultural e suas consequências

de si, mas que ele não admite que lhe são pertencentes ${ }^{36}$. O indivíduo desloca seu sentimento, por exemplo, para algo que está fora, isto é, ele projeta tal sentimento em algo.

Em "Notas psicanalíticas sobre um relato autobiográfico de um caso de paranoia"37 (Psychoanalytische Bemerkungen über einen autobiographisch beschriebenen Fall von Paranoia), texto escrito em 1911, Freud analisa um caso de paranoia a partir do livro Memórias de um doente dos nervos, escrito por Daniel Paul Schreber e publicado em 1903, onde o autor relata sua própria história enquanto doente. A partir da história clínica, Freud expõem algumas tentativas de explicação do caso, mencionando sua teoria da projeção como uma característica que pode ser facilmente notada nos sintomas da paranoia. No que se refere à projeção, de acordo com Fonseca e Mariano, Freud, no Caso Schreber, demonstrou que “[...] o sujeito paranoico projeta na pessoa ou grupo de pessoas os sentimentos, desejos, qualidades que existem no seu inconsciente, mas que não pode suportar e/ou admitir possuí-los" ${ }^{\text {38 }}$. Freud mostrou que a projeção é um mecanismo de defesa: os sentimentos indesejáveis, providos do inconsciente, são deformados e projetados em algo externo, protegendo, assim, a consciência.

Freud, na introdução do texto, diz que, uma vez que os paranoicos não podem ser levados a superar suas resistências internas (seus problemas), a paranoia pode ser um distúrbio passível de ser estudado com apenas um relato do próprio paciente, sem necessidade maior de se conhecer pessoalmente o paciente. É o que Freud faz em tais notas. Diante da publicação das Memórias de um doente dos nervos, escrito por Schreber, Freud toma a iniciativa de analisar o caso a partir desta autobiografia escrita pelo autor.

Na primeira parte do texto, Freud reconstrói a história clínica do paciente tentando apresentar, na medida do possível, uma anamnese completa para um bom diagnóstico. Assim, Freud menciona as primeiras doenças do paciente (hipocondria em 1885, insônia junto a alucinações em 1893, insanidade alucinatória e paranoia de 1894 em diante), os acontecimentos mais notáveis em sua vida (quando se apresenta como candidato ao Reichstag ${ }^{39}$ em 1884, quando toma posse no Landgericht $^{40}$ de Leipzig em 1886 e quando toma posse como juiz presidente em 1893), seus sonhos, suas internações (Asilo de Sonnenstein em 1884, Clínica de Leipzig em 1893, Asilo em Leipzig-Dösen em 1907) seus delírios, mediante trechos escritos pelo próprio autor-paciente e relatórios de seus médicos. Freud menciona, por exemplo, o relatório do Dr. Weber de 1899, onde Weber acentua dois pontos: descreve que o paciente, em seus delírios, tinha a crença de ter a missão de redimir o mundo (“delírio de Redentor”) e que, para isso,

\footnotetext{
${ }^{36}$ Fonseca, A. L. B; Mariano, M. S. S. "Desvendando o mecanismo da projeção", p. 3.

${ }^{37}$ Utilizo a tradução de José Octávio de Aguiar Abreu, publicada pela Imago Editora na Edição Standard Brasileira das Obras Psicológicas Completas de Sigmund Freud de 2006.

${ }^{38}$ Fonseca, A. L. B; Mariano, M. S. S. "Desvendando o mecanismo da projeção", p. 3.

${ }^{39}$ Segundo a nota do editor inglês na p. 18, é um importante cargo judiciário como juiz presidente do Landgericht (tribunal de jurisdição inferior) de Chemmitz.

${ }^{40}$ Cargo semelhante ao anterior.
}

\begin{tabular}{|c|c|c|c|c|c|}
\hline intuitio & $\begin{array}{c}\text { ISSN } \\
1983-4012\end{array}$ & Porto Alegre & Vol.8 $-\mathrm{N}^{\circ} .1$ & $\begin{array}{c}\text { Junho } \\
2015\end{array}$ & p.276-295 \\
\hline
\end{tabular}


Esquematismo, Mímese e falsa projeção: o modo de operação da indústria cultural e suas consequências

tinha de se transformar em mulher (emasculação) ${ }^{41}$. Também explica que o paciente tinha um delírio sexual de perseguição, primeiro o perseguidor era Flechsig, seu médico, depois Deus. No entanto, Freud chama atenção para a fantasia da emasculação afirmando que "a ideia de ser transformado em mulher foi a característica saliente e o germe mais primitivo de seu sistema delirante" ${ }^{\$ 2}$. Freud também menciona a importância e a complexidade da relação do paciente com a ideia de Deus, esforçando-se por explicar a visão teológica-psicológica de Schreber: suas opiniões sobre os nervos, o estado de beatitude, a hierarquia divina e os atributos de Deus, pois, de acordo com Freud, "nenhuma tentativa de explicar o caso Schreber terá possibilidade de ser correta, se não levar em consideração essas peculiaridades de sua concepção de Deus, essa mistura de reverência e rebeldia em sua atitude para com Ele" ${ }^{\text {"43 }}$. Desse modo, Freud conclui a primeira parte afirmando que os dois elementos principais dos delírios de Schreber - "sua transformação em mulher e sua relação favorecida com Deus" - demonstram uma relação genética ${ }^{44}$.

Na segunda parte do texto, tendo Freud já descrito a história clínica do paciente, procede com as tentativas de interpretação do caso. Neste ponto, é importante se ressaltar algo sobre o delírio de perseguição apresentado pelo paciente. Nota-se que Schreber apresentou inicialmente um quadro de delírios de perseguição, como afirma Freud: "pode-se acrescentar que havia certas pessoas por quem pensava estar sendo perseguido e prejudicado, e a quem dirigia vitupérios. A mais proeminente delas era seu médico anterior, Flechsig [...] ${ }^{, 45}$ Schreber, de início, culpava seu primeiro médico por persegui-lo, o Prof. Flechsig de Leipzig. Assim, quanto ao delírio de perseguição, Freud diz que a pessoa a quem o delírio atribui poder (no caso, Flechsig) é “[...] idêntica a alguém que desempenhou papel igualmente importante na vida emocional do paciente antes de sua enfermidade [...]”, podendo se dizer que tal delírio é um substituto daquela pessoa real influente. A emoção do paciente é projetada na forma de poder externo e sua qualidade (a qualidade da emoção) é transformada no oposto, isto é, a pessoa real que antes era amada, passa agora a ser odiada ${ }^{46}$. Portanto, o objetivo da perseguição, que se mostra através do delírio, é tentar encontrar justificativas para explicar sua mudança emocional, pois antes amava tal pessoa, agora passa a odiá-la (Schreber antes tinha apreço pelas pessoas reais, agora, através dos delírios e da projeção ("substiuição"), Flechsig o persegue e o incomoda). Nas palavras de Freud:

Parece que a pessoa a quem o delírio atribui tanto poder e influência, a cujas mãos todos os fios da conspiração convergem, é, se claramente nomeada, idêntica a alguém que desempenhou papel igualmente importante na vida emocional do paciente antes de sua enfermidade, ou facilmente reconhecível como substituto dela. A intensidade da emoção é projetada sob a forma de poder

\footnotetext{
${ }^{41}$ Freud. "Notas psicanalíticas sobre um relato autobiográfico de um caso de paranoia", p. 27.

${ }^{42}$ Freud. "Notas psicanalíticas sobre um relato autobiográfico de um caso de paranoia", p. 31.

${ }^{43}$ Freud. "Notas psicanalíticas sobre um relato autobiográfico de um caso de paranoia", p. 38.

${ }^{44}$ Freud. "Notas psicanalíticas sobre um relato autobiográfico de um caso de paranoia", p. 44.

${ }^{45}$ Freud. "Notas psicanalíticas sobre um relato autobiográfico de um caso de paranoia", p. 25.

${ }^{46}$ Freud. "Notas psicanalíticas sobre um relato autobiográfico de um caso de paranoia”, p. 50.
}

\begin{tabular}{|c|c|c|c|c|c|}
\hline intuitio & $\begin{array}{c}\text { ISSN } \\
1983-4012\end{array}$ & Porto Alegre & Vol.8 $-\mathrm{N}^{\circ} .1$ & $\begin{array}{c}\text { Junho } \\
2015\end{array}$ & p.276-295 \\
\hline
\end{tabular}


Esquematismo, Mímese e falsa projeção: o modo de operação da indústria cultural e suas consequências

externo, enquanto sua qualidade é transformada no oposto. A pessoa agora odiada e temida, por ser um perseguidor, foi, noutra época, amada e honrada. O principal propósito da perseguição asseverada pelo delírio do paciente é justificar a modificação em sua atitude emocional ${ }^{47}$.

Freud, analisando tal caso à luz da teoria da projeção, diz que o problema provavelmente se deve a uma manifestação de "libido ${ }^{48}$ homossexual". O apreço que Schreber tinha com seu médico Flechsig (depois de ter sido curado por este) gerou um sentimento afetuoso de dependência de Schreber em relação a seu médico, tal apreço apareceu novamente mais tarde e em um grau muito maior, chegando a se constituir como desejo erótico. Tal desejo foi responsável por motivar as fantasias femininas de Schreber. Uma vez que tais fantasias entraram em embate com um tipo de "protesto masculino", elas acabaram vencendo. A causa da doença, então, foi uma libido homossexual, o objeto da libido foi o médico Flechsig, e as lutas de Schreber contra tais desejos homossexuais produziram um conflito que deu origem aos sintomas, como os delírios de perseguição, por exemplo ${ }^{49}$. O porquê de tal embate ter dado origem aos delírios de perseguição, Freud afirma não saber, mas que bem poderia ter originado outra coisa ${ }^{50}$. No entanto, de acordo com Freud, o ego do paciente “[...] encontrava satisfação na megalomania[ $\left[{ }^{51}\right]$, enquanto que sua fantasia feminina de desejo avançava e tornava-se aceitável" ${ }^{\text {"52 }}$. O paciente que acreditava ser vítima de perseguição, tentando explicar seu próprio caso, passa a se sentir como uma espécie de escolhido, o que explica a megalomania. Novamente se salienta que os delírios de perseguição, por sua vez, se agravaram a ponto do paciente substituir o seu médico Flechsig por Deus. Desse modo, diante dos dois perseguidores (Flechsig e Deus) e diante do agravamento da doença (Flechsig é o primeiro perseguidor e Deus o segundo), Freud explica que provavelmente Flechsig aparece primeiro como perseguidor substituindo alguém que o paciente amava, provavelmente seu irmão já falecido. Com o agravamento da doença, o paciente passa a culpar Deus de persegui-lo, Deus seria, assim, o substituto de alguém que o paciente amava em grau ainda maior, provavelmente seu pai, também já falecido ${ }^{53}$, o que configura um complexo paterno.

Na terceira e última parte do texto, Freud diz que, apesar de toda a análise já feita, não há nada que caracterize a paranoia. A paranoia deve ser procurada na forma que assume os sintomas, neste caso,

\footnotetext{
${ }^{47}$ Freud. "Notas psicanalíticas sobre um relato autobiográfico de um caso de paranoia", p. 50.

48 De acordo com Freud, "libido é expressão extraída da teoria das emoções. Damos esse nome à energia, considerada como uma magnitude quantitativa (embora na realidade não seja presentemente mensurável), daqueles instintos que têm a ver com tudo o que pode ser abrangido sob a palavra 'amor'." Freud. "Psicologia de grupo e a análise do ego", p. 101.

${ }^{49}$ Freud. "Notas psicanalíticas sobre um relato autobiográfico de um caso de paranoia”, p. 52.

${ }^{50}$ Freud. "Notas psicanalíticas sobre um relato autobiográfico de um caso de paranoia", p. 56.

51 "Uma supervalorização sexual do ego" Freud. "Notas psicanalíticas sobre um relato autobiográfico de um caso de paranoia", p. 73.

${ }_{52}^{5}$ Freud. "Notas psicanalíticas sobre um relato autobiográfico de um caso de paranoia", p. 57.

${ }^{53}$ Freud. "Notas psicanalíticas sobre um relato autobiográfico de um caso de paranoia”, p. 59.
}

\begin{tabular}{|c|c|l|l|c|c|}
\hline intuitio & $\begin{array}{c}\text { ISSN } \\
1983-4012\end{array}$ & Porto Alegre & Vol.8 $-\mathrm{N}^{\circ} .1$ & $\begin{array}{c}\text { Junho } \\
2015\end{array}$ & p.276-295 \\
\hline
\end{tabular}


paranoico "[...] foi o fato de o paciente, para repelir uma fantasia de desejo homossexual, ter reagido precisamente com delírios de perseguição desta espécie" ${ }^{, 54}$. O que está no centro do conflito, nos casos de paranoia em indivíduos do sexo masculino, é uma fantasia sexual: um homem que ama outro homem. Assim, Freud diz que uma proposição do tipo "eu (um homem) o amo" 55 é modificada pelos delírios de perseguição, resultando numa proposição (enunciada no inconsciente) do tipo "eu não o amo - Eu o odeio" 56 . Porém, as percepções ou sentimentos internos (o amor por um homem agora, mediante os delírios, transformados em ódio) devem ser substituídos por percepções ou sentimentos externos: devem ser projetados em outra pessoa. Freud afirma que a característica que pode ser mais facilmente notada nos sintomas da paranoia é o processo de projeção.

Tendo explicado o mecanismo da projeção em Freud, e concluindo estas duas primeiras seções como fundamento para as seções subsequentes, as três últimas partes deste artigo explicarão, com base no que já foi construído, a relação da indústria cultural com o esquematismo e a mimese e a relação do indivíduo (semiformado, isto é, submetido às regras da indústria cultural) com a teoria de Adorno e Horkheimer da falsa projeção.

\section{O esquematismo da produção pela indústria cultural}

$\mathrm{Na}$ medida em que o esquema kantiano se apresenta como um pensamento de um conceito como uma regra geral e uma vez que tal esquema, grosso modo, sintetiza representações particulares via intuição (sendo o esquema, dessa forma, uma mediação entre a faculdade da sensibilidade e a faculdade do entendimento), ele pode ser compreendido como o processo pelo qual o entendimento opera (trabalha) com os esquemas. Ora, uma vez que Kant afirma que a representação de um objeto (particular) no entendimento deve ser homogênea ao seu conceito (geral), o esquema homogeneíza as faculdades heterogêneas, ele parece fornecer um modelo ao conceito, ou ainda, parece acomodar uma representação particular a um conceito geral, uma verdadeira subsunção. Tal subsunção é o procedimento adotado pela indústria cultural. "O esquematismo do procedimento mostra-se no fato de que os produtos mecanicamente diferenciados acabam por se revelar sempre como a mesma coisa" ${ }^{, 57}$. Assim, pode-se afirmar que a indústria cultural produz os esquemas.

\footnotetext{
${ }^{54}$ Freud. "Notas psicanalíticas sobre um relato autobiográfico de um caso de paranoia", p. 67.

${ }^{55}$ Freud. "Notas psicanalíticas sobre um relato autobiográfico de um caso de paranoia", p. 71.

${ }^{56}$ Freud. "Notas psicanalíticas sobre um relato autobiográfico de um caso de paranoia", p. 71.

57 Adorno e Horkheimer. "A indústria cultural: o esclarecimento como mistificação das massas", Dialética do esclarecimento, p. 102.
}

\begin{tabular}{|c|c|c|c|c|c|}
\hline intuitio & $\begin{array}{c}\text { ISSN } \\
1983-4012\end{array}$ & Porto Alegre & Vol.8- No.1 & $\begin{array}{c}\text { Junho } \\
2015\end{array}$ & p.276-295 \\
\hline
\end{tabular}


Esquematismo, Mímese e falsa projeção: o modo de operação da indústria cultural e suas consequências

Adorno e Horkheimer se referem ao esquematismo no excurso 2, intitulado "Juliete ou esclarecimento e moral" da Dialética do esclarecimento ${ }^{58}$ (Dialektik der Aufklärung), quando explicam que o esclarecimento de Kant é a saída do homem de sua condição de menoridade (onde o entendimento é dirigido por outrem), assim, o homem uma vez liberto, passa a dirigir seu intelecto pela razão. A razão estabelece certa unidade de conhecimentos, um sistema onde ocorrem conexões de conhecimentos a partir de um princípio, ela deriva o particular do universal. $O$ esquematismo garante a homogeneidade do universal e do particular. Desse modo, os autores explicam que tal homogeneidade operada pelo esquematismo é um "funcionamento inconsciente" que faz uma correspondência entre a percepção e o entendimento $^{59}$. Continuando a abordagem sobre o conceito de razão, Adorno e Horkheimer apontam algumas obscuridades na Crítica da razão pura, pois a mesma razão que propicia a liberdade também é sujeita à manipulação ${ }^{60}$.

A verdadeira natureza do esquematismo, que consiste em harmonizar exteriormente o universal e o particular, o conceito e a instância singular, acaba por se revelar na ciência atual como o interesse da sociedade industrial. O ser é intuído sob o aspecto da manipulação e da administração ${ }^{61}$.

O homem se converte em um processo substituível, um exemplo para os modelos do sistema. "Os sentidos já estão condicionados pelo aparelho conceitual antes que a percepção ocorra [...]"62 Isto é, antes mesmo do objeto aparecer à sensibilidade do indivíduo com a propriedade "x", tal propriedade já é embutida no objeto na ocasião de sua produção. Os produtos são fabricados para o consumo: são fabricados segundo os padrões do próprio entendimento, pois a indústria cultural é a racionalização imposta do alto. “[...] A razão só entende aquilo que produz segundo os seus próprios planos [...]”,63, dizia Kant. Tal procedimento descrito por Kant é, segundo Adorno e Horkheimer, praticado conscientemente pela indústria cultural:

Kant antecipou intuitivamente o que só Hollywood realizou conscientemente: as imagens já são pré-censuradas por ocasião de sua própria produção segundo os padrões do entendimento que decidirá depois como devem ser vistas. A percepção pela qual o juízo público se encontra confirmado já estava preparada por ele antes mesmo de surgir ${ }^{64}$.

Antes mesmo dos indivíduos terem acesso ao produto veiculado, tal produto já foi conscientemente operado no processo de produção. Os sentidos já estão condicionados a priori pela

\footnotetext{
${ }_{58}^{58}$ Utilizo a tradução do professor Guido Antonio de Almeida, publicada pela editora Zahar em 2006.

${ }^{59}$ Adorno e Horkheimer. "Excurso II: Juliete ou esclarecimento e moral", Dialética do esclarecimento, p. 71-72.

${ }^{60}$ Adorno e Horkheimer. "Excurso II: Juliete ou esclarecimento e moral”, Dialética do esclarecimento, p. 73.

${ }^{61}$ Adorno; Horkheimer. "Excurso II: Juliete ou esclarecimento e moral”, Dialética do esclarecimento, p. 73.

${ }^{62}$ Adorno; Horkheimer. "Excurso II: Juliete ou esclarecimento e moral", Dialética do esclarecimento, p. 73.

${ }^{63}$ CRP, B XIII.

${ }^{64}$ Adorno; Horkheimer. "Excurso II: Juliete ou esclarecimento e moral”, Dialética do esclarecimento, p. 73.
}

\begin{tabular}{|c|c|c|c|c|c|}
\hline intuitio & $\begin{array}{c}\text { ISSN } \\
1983-4012\end{array}$ & Porto Alegre & Vol.8 $-\mathrm{N}^{\mathrm{o}} .1$ & $\begin{array}{c}\text { Junho } \\
2015\end{array}$ & p.276-295 \\
\hline
\end{tabular}


indústria cultural de tal modo que os produtos são pré-digeridos ${ }^{65}$. "Seja o que for passar às massas já deve ter sido operado, manipulado e aprovado por centenas de milhares de pessoas antes mesmo de qualquer um poder apreciá-lo"66. E é claro que tal procedimento também se aplica à arte, no entanto, Adorno dirá que a arte ainda possui um poder de superação em relação à cultura de massa:

Certamente que cada obra de arte acabada já é predeterminada de alguma maneira, mas a arte se esforça para superar seu próprio peso opressivo como um artefato por meio da força de sua própria construção. A cultura de massa, por outro lado, simplesmente se identifica com o curso da predeterminação e alegremente se satisfaz ${ }^{67}$.

Outra referência de Adorno e Horkheimer ao esquematismo kantiano se encontra no capítulo sobre a indústria cultural, onde os autores comentam que

a função que o esquematismo kantiano ainda atribuía ao sujeito, a saber, referir de antemão a multiplicidade sensível aos conceitos fundamentais, é tomada ao sujeito pela indústria. $\mathrm{O}$ esquematismo é o primeiro serviço prestado por ela ao cliente. $\mathrm{Na}$ alma devia atuar um mecanismo secreto destinado a preparar os dados imediatos de modo a se ajustarem ao sistema da razão pura. Mas o segredo está hoje decifrado. Muito embora o planejamento do mecanismo pelos organizadores dos dados, isto é, pela indústria cultural, seja imposto a esta pelo peso da sociedade que permanece irracional apesar de toda racionalização, essa tendência fatal é transformada em sua passagem pelas agências do capital do modo a aparecer como o sábio designo dessas agências. Para o consumidor, não há mais a classificar que não tenha sido antecipado no esquematismo da produção ${ }^{68}$.

Segundo Rodrigo Duarte, “[...] atualmente a contrapartida real dos objetos estéticos (obras de arte, por exemplo) é a triunfante tentativa de controle completo dos modos de percepção a partir dos 'esquemas' fornecidos pela indústria cultural”' ${ }^{\prime 2}$. As pessoas se orientam pelos produtos massificados, produtos da estereotipia. Os esquemas veiculados pela indústria esquematizam os indivíduos. Se já não há muita diferença entre a série Chrysler e a série General Motors, como dizem os autores, se já não há muita diferença entre uma música gravada por uma dupla sertaneja no ano passado e uma música laçada por

\footnotetext{
${ }^{65}$ Referência como essa, também pode ser encontrada no trecho: "a música popular é 'pré-digerida', de um modo bastante similar à moda dos digest de material impresso." Adorno. "Sobre música popular", Theodor W. Adorno. Col. Grandes Cientistas Sociais, p. 121.

66 "Whatever is to pass muster must already have been handled, manipulated and approved by hundreds of thousands of people before anyone can enjoy it." Adorno. "The schema of mass culture", The culture industry, p. 67. Tradução minha. O vocábulo "muster", no inglês, foi vertido para "massa" afim de manter a frase mais inteligível de acordo com o contexto a que está inserida (assim, neste contexto, "muster" se aproxima mais de seu sinônimo "group").

67 "Certainly every finished work of art is already predetermined in some way but art strives to overcome its own oppressive weight as an artefact through the force of its very construction. Mass culture on the other hand simply identifies with the curse of predetermination and joyfully fulfils it." Adorno. "The schema of mass culture", The culture industry, p. 67. Tradução minha.

${ }^{68}$ Adorno e Horkheimer. "A indústria cultural: o esclarecimento como mistificação das massas", Dialética do esclarecimento, p. 103.

${ }^{69}$ Rodrigo Duarte. "O esquematismo Kantiano e a crítica à indústria cultural”, p. 85.
}

\begin{tabular}{|c|c|l|l|l|l|}
\hline intuitio & $\begin{array}{c}\text { ISSN } \\
1983-4012\end{array}$ & Porto Alegre & Vol.8 $-\mathrm{N}^{\mathrm{o}} .1$ & $\begin{array}{c}\text { Junho } \\
2015\end{array}$ & p.276-295 \\
\hline
\end{tabular}


Esquematismo, Mímese e falsa projeção: o modo de operação da indústria cultural e suas consequências

outra dupla hoje, pode-se dizer que já não há mais diferença entre os indivíduos: eles são cooptados pela estereotipia, assim como os produtos.

Diante do exposto, é importante ressaltar que além da pequena "diferença de registro" de Kant em relação a Adorno e Horkheimer ${ }^{70}$, no que se refere ao esquematismo, não há uma exposição mais detalhada por parte dos autores em relação ao modo pelo qual a indústria cultural se apropria do esquematismo $^{71}$. Da mesma forma e, de modo mais geral, apesar de toda a exposição sobre a indústria cultural, seu modo de operação, manipulação e dos efeitos que ela causa, aparentemente não há, declaradamente, uma exposição que aponte para o modo da indústria cultural operar no indivíduo do ponto de vista psicológico do próprio indivíduo. E é desse modo que aqui se propõe a entender que parte do capítulo sobre o antissemitismo, ao abordar o esquematismo ${ }^{72}$, a mimese e a falsa projeção, constitui alguns elementos essenciais da exposição do funcionamento da indústria cultural. Vale lembrar que os autores reutilizaram o conceito de esquematismo conservando sua característica kantiana da possibilidade de significação do mundo fenomênico, vinculando-o ao conceito freudiano de projeção.

\section{Mimese}

$\mathrm{Na}$ seção V do capítulo intitulado "Elementos do antissemitismo: limites do esclarecimento", Adorno e Horkheimer começam por demonstrar a característica da idiossincrasia ${ }^{73}$ (Idiosynkrasie) nos antissemitas. A emancipação da sociedade ao antissemitismo depende da possibilidade de se elevar o conteúdo particular (da idiossincrasia) ao geral (ao conceito), pois se considera como natural tudo o que é geral (assim, ao se elevar algo que é particular, como o antissemitismo, ao geral, torna-se natural): "o que se considera como natural é o universal, o que se encaixa no contexto funcional da sociedade"74. Acrescenta-se ainda que a questão do gosto também pode ser compreendida sob esses aspectos. Tudo o que se encaixa num quadro geral é tomado como natural, o que não se enquadra, provoca repugnância.

\footnotetext{
${ }^{70}$ Conforme explica Rodrigo Duarte, "para Kant, [...] o esquematismo se refere fundamentalmente às condições de constituição do objeto de conhecimento para o sujeito transcendental. Já nas colocações de Adorno e Horkheimer, o que está em questão é o modo como se forma a percepção num sentido muito mais geral [...]” Rodrigo Duarte. "O esquematismo kantiano e a crítica à indústria cultural", p. 102-103.

${ }^{71}$ Rodrigo Duarte. "Esquematismo e semiformação", p. 450.

${ }^{71}$ Rodrigo Duarte. "Esquematismo e semiformação", p. 449.

72 Essa afirmação se baseia em uma observação de Rodrigo Duarte: "apesar de nesse texto ["Elementos do antissemitismo"] os autores não usarem explicitamente o termo 'esquematismo', pode-se constatar facilmente a inspiração desse capítulo da Crítica da razão pura no conceito de 'falsa projeção', sobre o qual eles baseiam sua elucidação crítica do anti-semitismo." Rodrigo Duarte. "O esquematismo kantiano e a crítica à indústria cultural”, p. 100.

${ }^{73} \mathrm{O}$ vocábulo "Idiosynkrasie", por não haver muitos problemas aqui, pode ser pensado como "particularidade".

${ }^{74}$ Adorno e Horkheimer. "Elementos do antissemitismo: limites do esclarecimento", Dialética do esclarecimento, p. 148.
}

\begin{tabular}{|c|c|c|c|c|c|}
\hline intuitio & $\begin{array}{c}\text { ISSN } \\
1983-4012\end{array}$ & Porto Alegre & Vol.8 $-\mathrm{N}^{\circ} .1$ & $\begin{array}{c}\text { Junho } \\
2015\end{array}$ & p.276-295 \\
\hline
\end{tabular}


Esquematismo, Mímese e falsa projeção: o modo de operação da indústria cultural e suas consequências

Para Adorno e Horkheimer, o sujeito, naturalmente ou biologicamente, imita a natureza: "a proteção pelo susto é uma forma de mimetismo" 75 . Por exemplo, diante de um sinal de perigo (expresso pela natureza) a idiossincrasia, do ponto de vista dos autores, é explicada como um processo em que determinados órgãos escapam do domínio do sujeito e, independentes, passam a obedecer estímulos biológicos fundamentais (uma vez que o ego perde relativamente o controle). Nesse momento, essas reações efetuam uma assimilação: assimilam algo do ambiente (imitam o estímulo provindo do ambiente). Os autores também afirmam que "quando o humano quer se tornar como a natureza, ele se enrijece contra ela"76. Isto é, quando o indivíduo se identifica com algo na natureza (quando entra em contato e cria afeto com algo), ele se "volta contra" ela, num processo que parece lembrar um pouco o mecanismo de defesa da projeção, como descrito por Freud, assim, reafirmando a relação entre o indivíduo e a natureza. Os autores também demonstram que a civilização mantém desde a "fase mágica" um comportamento mimético, e que tal comportamento é apropriado - manipulado - pelos líderes fascistas, por exemplo. Todo o comportamento humano é mimético. O ego se forjou ao se fortalecer contra o mimetismo: a cada estímulo recebido do meio, o sujeito se volta contra ele (no sentido de se proteger), mas ao mesmo tempo o assimila. Por exemplo, quando o indivíduo escuta um trovão, seus órgãos escapam do seu domínio (consciente) e passam a obedecer aos estímulos biológicos, imitam o trovão quando o sistema se desestabiliza pelo susto. Segundo os autores, é dessa forma de constituição do ego "[...] que se realiza a passagem da mimese refletora para a reflexão controlada" ${ }^{, 77}$. Sobre essa questão, segundo Rodrigo Duarte, o comportamento mimético que se poderia chamar de "normal" "[...] se encontra sedimentado como uma das ações mais elementares da existência humana, a qual, entretanto, é apropriada pelos líderes fascistas no sentido de impor um padrão de conduta aos seus adeptos, a ser acriticamente reproduzido" ${ }^{, 78}$. A imitação, portanto, estabelece-se como meio de dominação. A indústria cultural imprimi moldes que são facilmente assimilados e imitados.

De fato, a indústria cultural colocou a imitação como algo de absoluto ${ }^{79}$. Os homens só percebem os seus traços miméticos, isto é, que seu comportamento é automatizado, quando vê o traço mimético no outro. A imitação é transmitida, inconscientemente, de geração em geração e o que se perde - nas mãos da civilização repressora - são as características mais humanas que acabam sendo tomadas como estranhas ${ }^{80}$.

\footnotetext{
${ }^{75}$ Adorno e Horkheimer. "Elementos do antissemitismo: limites do esclarecimento", Dialética do esclarecimento, p. 149.

${ }^{76}$ Adorno e Horkheimer. "Elementos do antissemitismo: limites do esclarecimento", Dialética do esclarecimento, p. 149.

${ }^{77}$ Adorno e Horkheimer. "Elementos do antissemitismo: limites do esclarecimento", Dialética do esclarecimento, p. 149.

${ }^{78}$ Rodrigo Duarte. "Esquematismo e semiformação", p. 450.

79 Adorno e Horkheimer. "A indústria cultural: o esclarecimento como mistificação das massas", Dialética do esclarecimento, p. 108.

80 "O que repele por sua estranheza é, na verdade, demasiado familiar. São os gestos contagiosos dos contatos diretos
}

\begin{tabular}{|c|c|c|c|c|c|}
\hline intuitio & $\begin{array}{c}\text { ISSN } \\
1983-4012\end{array}$ & Porto Alegre & Vol.8 $-\mathrm{N}^{\circ} .1$ & $\begin{array}{c}\text { Junho } \\
2015\end{array}$ & p.276-295 \\
\hline
\end{tabular}


A própria civilização, por ser repressora, inibe os impulsos naturais do homem operando uma inversão ${ }^{81}$. "A civilização é a vitória da sociedade sobre a natureza [...]" ${ }^{\text {"82 }}$ Posto isso, é de se notar que os autores, evidentemente, levantaram a questão da mimese para demonstrar como os antissemitas fizeram uso de tal recurso para alastrar o antissemitismo, no entanto, igualmente, defendem que é devido à ela que se tem um processo de padronização dos produtos e dos comportamentos. Da mesma forma que os fascistas usavam fórmulas fixas e, repetindo tais fórmulas, conseguiam criar um padrão de comportamento para os oficiais, para os alemães e para os condenados ${ }^{83}$, a publicidade - por ser uma das vozes da indústria cultural -, por exemplo, também utiliza de fórmulas que são congeladas e reproduzidas continuamente.

\section{Falsa projeção}

Uma vez que já se explicou o mecanismo da projeção ${ }^{84}$ de acordo com Freud, e o conceito de mimese como é apresentado pelos autores na seção do capítulo sobre o antissemitismo, pode-se passar para o conceito de falsa projeção, como é apresentado na seção VI.

Como se viu, a indústria cultural manipula através da mimese (divulga um tipo de pensamento e comportamento e o indivíduo o repete), no entanto, como o material divulgado pela indústria cultural é semiformado - falso -, a mimese que a indústria propaga é uma falsa mimese. Assim, quando o indivíduo projeta seus impulsos no meio, realiza uma falsa projeção. Segundo os autores, "o antissemitismo baseiase numa falsa projeção. Ele é o reverso da mimese genuína, profundamente aparentada à mimese que foi recalcada, talvez o traço caracterial patológico em que esta se sedimenta" ${ }^{\text {}}$. O antissemita quer tornar o mundo semelhante a ele, seus impulsos inadmissíveis são atribuídos ao objeto, ao semita que se coloca como vítima. De modo diferente da mimese, que torna o indivíduo semelhante ao que está no mundo exterior, o mecanismo da falsa projeção torna o que está no mundo exterior semelhante ao indivíduo: “só a mimese se torna semelhante ao mundo ambiente, a falsa projeção torna o mundo ambiente semelhante a

reprimidos pela civilização: tocar, aconchegar-se, aplacar, induzir." Adorno e Horkheimer. "Elementos do antissemitismo: limites do esclarecimento", Dialética do esclarecimento, p. 150.

${ }^{81}$ Os aspectos mais naturais do homem (tocar, abraçar) acabam sendo tomados como estranhos, e o que era pra ser estranho (como determinados comportamentos impostos pelos antissemitas, ou pela própria indústria cultural) como natural.

${ }^{82}$ Adorno e Horkheimer. "Elementos do antissemitismo: limites do esclarecimento", Dialética do esclarecimento, p. 153.

${ }^{83}$ Adorno e Horkheimer. "Elementos do antissemitismo: limites do esclarecimento", Dialética do esclarecimento, p. 152.

${ }^{84}$ Adorno e Horkheimer também explicam, resumidamente, o mecanismo da projeção na seção VI dos "Elementos do antissemitismo". Adorno e Horkheimer. "Elementos do antissemitismo: limites do esclarecimento", Dialética do esclarecimento, p. 158.

${ }^{85}$ Adorno e Horkheimer. "Elementos do antissemitismo: limites do esclarecimento", Dialética do esclarecimento, p. 154.

\begin{tabular}{|c|c|c|c|c|c|}
\hline intuitio & $\begin{array}{c}\text { ISSN } \\
1983-4012\end{array}$ & Porto Alegre & Vol.8- No.1 & $\begin{array}{c}\text { Junho } \\
2015\end{array}$ & p.276-295 \\
\hline
\end{tabular}


Esquematismo, Mímese e falsa projeção: o modo de operação da indústria cultural e suas consequências

ela" ${ }^{\sharp 6}$. Portanto, enquanto a projeção é um mecanismo em que o indivíduo transfere seus impulsos para o objeto, a falsa projeção é um mecanismo em que o indivíduo semiformado transfere seus impulsos doentios para o objeto; é um distúrbio da capacidade de perceber o exterior.

Segundo Adorno e Horkheimer, a projeção é um mecanismo que já está automatizado nos homens, da mesma forma como as outras funções, como o ataque e a proteção, que já se tornaram reflexos e, igualmente, automatizados. A projeção, por ser espontânea, propicia que o mundo se torne objetivo para os homens, como algo inconsciente ${ }^{87}$. Quando o indivíduo percebe alguma coisa no meio externo, ele reage, inconsciente e espontaneamente, ao meio, projetando algo seu (como um movimento de proteção, um impulso) e é por isso que os autores afirmam que "perceber é projetar" 88 .

O antissemitismo, de acordo com os autores, é patológico não no sentido de ser projetivo, mas de ser uma projeção irracional. Assim como o antissemitismo se caracteriza como um comportamento irracional, a indústria cultural também transfere um comportamento que é reproduzido de modo irracional. Os sujeitos não são comparados a autômatos à toa, mas por se enquadrarem em esquemas de comportamentos acríticos e, portanto, irracionais. O sujeito, como consumidor, perde a capacidade de reflexão sobre o objeto e sobre si mesmo:

O patológico no antissemitismo não é o comportamento projetivo enquanto tal, mas a ausência da reflexão que o caracteriza. Não conseguindo mais devolver ao objeto o que dele recebeu, o sujeito não se torna mais rico, porém, mais pobre. Ele perde a reflexão nas duas direções: como não reflete mais o objeto, ele não reflete mais sobre si e perde assim a capacidade de diferenciar ${ }^{89}$.

Desde a ascensão da espécie humana, o homem se mostra, entre os animais, como o mais evoluído e possuidor do maior poder de destruição. No centro entre as espécies, as mantém impotente assim como a natureza, projetando suas desgraças para ela. Vendo a natureza como um mistério, o mito medieval do diabo, as seitas e as crendices contribuíram para dar sentido ao mundo exterior incompreendido e também para bloquear o pensamento. Hoje, com a dominação do mercado que extingue a cultura, surgem novas condições para a paranoia das massas; o homem não atingiu a emancipação e a cultura adoeceu se transformando em mercadoria. Desse modo, pode-se compreender que o homem realiza uma falsa projeção porque é semicultivado, projeta um material derivado da semicultura. Recebe, mediante a mimese, estímulos da cultura industrializada e, uma vez semiformado, projeta seus impulsos enquanto

\footnotetext{
${ }^{86}$ Adorno e Horkheimer. "Elementos do antissemitismo: limites do esclarecimento", Dialética do esclarecimento, p. 154.

${ }^{87}$ Adorno e Horkheimer. "Elementos do antissemitismo: limites do esclarecimento", Dialética do esclarecimento, p. 155.

${ }^{88}$ Adorno e Horkheimer. "Elementos do antissemitismo: limites do esclarecimento", Dialética do esclarecimento, p. 154.

${ }^{89}$ Adorno e Horkheimer. "Elementos do antissemitismo: limites do esclarecimento", Dialética do esclarecimento, p. 156.
}

\begin{tabular}{|c|c|c|c|c|r|}
\hline intuitio & $\begin{array}{c}\text { ISSN } \\
1983-4012\end{array}$ & Porto Alegre & Vol.8 $-\mathrm{N}^{\mathrm{o}} .1$ & $\begin{array}{c}\text { Junho } \\
2015\end{array}$ & p.276-295 \\
\hline
\end{tabular}


consumidor. No plano do nazismo, enquanto a paranoia é o sintoma do antissemita que persegue os judeus, no plano do mercado, ela também é o sintoma do sujeito contemporâneo que persegue, de modo doentio, os produtos.

A tendência à falsa projeção é tão fatalmente inerente ao espírito que ela, esquema isolado da autoconservação, ameaça dominar tudo o que vai além dela: a cultura. A falsa projeção é o usurpador do reino da liberdade e da cultura; a paranoia é o sintoma do indivíduo semicultivado ${ }^{90}$.

Por conseguinte, é importante lembrar que os autores afirmam que "a emancipação individual e social da dominação é o movimento contrário à falsa projeção [...]"91 porque o indivíduo, uma vez que se desprende da semicultura e da indústria cultural, passa a projetar naturalmente e não mais patologicamente, passa a projetar seus impulsos na natureza, mas que não são mais impulsos semiformados.

\section{Considerações finais}

A explicação do caráter mimético da civilização junto a teoria do esquematismo e da falsa projeção apresentada por Adorno e Horkheimer no capítulo sobre o antissemitismo parece ser, como a ordem dentro do livro mesmo aponta, uma continuação da explicação da indústria cultural apresentada no capítulo anterior. A abordagem da indústria cultural geralmente é centrada pelos comentadores no capítulo sobre a indústria cultural e raramente coadunada com as teorias desenvolvidas no capítulo seguinte. Assim, compreende-se que essas três abordagens, a saber, o esquematismo, a mimese e a falsa projeção, são fortes ferramentas para a compreensão do modo de funcionamento da indústria cultural e sua relação com o sujeito semiformado e alienado. No entanto, é importante ressaltar que, evidentemente, não são a únicas abordagens nem as mais importantes. Não se pode esquecer o peso que tem os outros conceitos oferecidos pelos autores, e em especial por Adorno, que também - como a alienação, a ideologia, o fetichismo, a padronização e a semiformação, para citar alguns - fazem parte do processo de compreensão do fenômeno indústria cultural.

\section{Referências bibliográficas}

\footnotetext{
${ }^{90}$ Adorno e Horkheimer. "Elementos do antissemitismo: limites do esclarecimento", Dialética do esclarecimento, p. 161.

${ }^{91}$ Adorno e Horkheimer. "Elementos do antissemitismo: limites do esclarecimento", Dialética do esclarecimento, p. 164.
}

\begin{tabular}{|c|c|c|c|c|c|}
\hline intuitio & $\begin{array}{c}\text { ISSN } \\
1983-4012\end{array}$ & Porto Alegre & Vol.8 $-\mathrm{N}^{\mathrm{o}} .1$ & $\begin{array}{c}\text { Junho } \\
2015\end{array}$ & p.276-295 \\
\hline
\end{tabular}


Esquematismo, Mímese e falsa projeção: o modo de operação da indústria cultural e suas consequências

ADORNO, Theodor W.; HORKHEIMER, Max. Dialética do esclarecimento: fragmentos filosóficos. Tradução de Guido Antonio de Almeida. Rio de Janeiro: Jorge Zahar, 2010.

. Sobre música popular. In: ADORNO. Theodor W. COHN, Gabriel (org.). Theodor W. Adorno. Tradução de

Flávio R. Kothe, Aldo Onesti e Amélia Cohn. São Paulo: Ática, 1986. (Grandes cientistas sociais)

. The schema of mass culture. In: ADORNO. Theodor W. The culture industry: selected essays on mass culture. London and New York: Routledge, 2005.

DUARTE. Rodrigo. Esquematismo e semiformação. Educ. Soc., Campinas, v. 24, n. 83, p. 441-457, ago. 2003.

. O esquematismo kantiano e a crítica à indústria cultural. Studia Kantiana, v. 4, n. 1, p. 85-105, 2003.

FONSECA, Ana Lucia Barreto de; MARIANO, Maria do Socorro Sales. Desvendando o mecanismo da projeção. Psicologia \&m Foco, Aracaju, v. 1, n. 1, p. 1-8, Jul/dez. 2008.

FREUD, Sigmund. Notas psicanalíticas sobre um relato autobiográfico de um caso de paranoia (dementia paranoides). In: FREUD, Sigmund. Obras psicológicas completas de Sigmund Freud. Tradução de The standard edition of the complete psychological works of Sigmund Freud. v. XII. Rio de Janeiro: Imago, 2006.

. Psicologia de grupo e a análise do ego. In: FREUD, Sigmund. Obras psicológicas completas de Sigmund

Freud. Tradução de The standard edition of the complete psychological works of Sigmund Freud. v. XVIII. Rio de Janeiro: Imago, 2006.

KANT, Immanuel. Crítica da razão pura. $5^{\text {a }}$ ed. Tradução de Manuela Pinto dos Santos e Alexandre Fradique Morujão. Introdução e notas de Alexandre Fradique Morujão. Lisboa: Fundação Calouste Gulbenkian, 2001.

. Prolegômenos. Tradução de Tania Maria Bernkopf. São Paulo: Abril Cultural,1974. (Os pensadores)

MARQUES, Ubirajara Rancan de Azevedo. Notas sobre o esquematismo na Crítica da razão pura de Kant. Trans/Form/Ação, São Paulo, 18, p. 121-140, 1995.

Recebido em: 25/09/2014

Aprovado para publicação em: 19/05/2015

\begin{tabular}{|c|c|c|c|c|c|}
\hline intuitio & $\begin{array}{c}\text { ISSN } \\
1983-4012\end{array}$ & Porto Alegre & Vol.8 $-\mathrm{N}^{\circ} .1$ & $\begin{array}{c}\text { Junho } \\
2015\end{array}$ & p.276-295 \\
\hline
\end{tabular}

